\title{
A PESQUISA QUALITATIVA E SUA UTILIZAÇÃO EM ADMINISTRAÇÃO DE EMPRESAS
}

$\star$ Arilda Schmidt Godoy

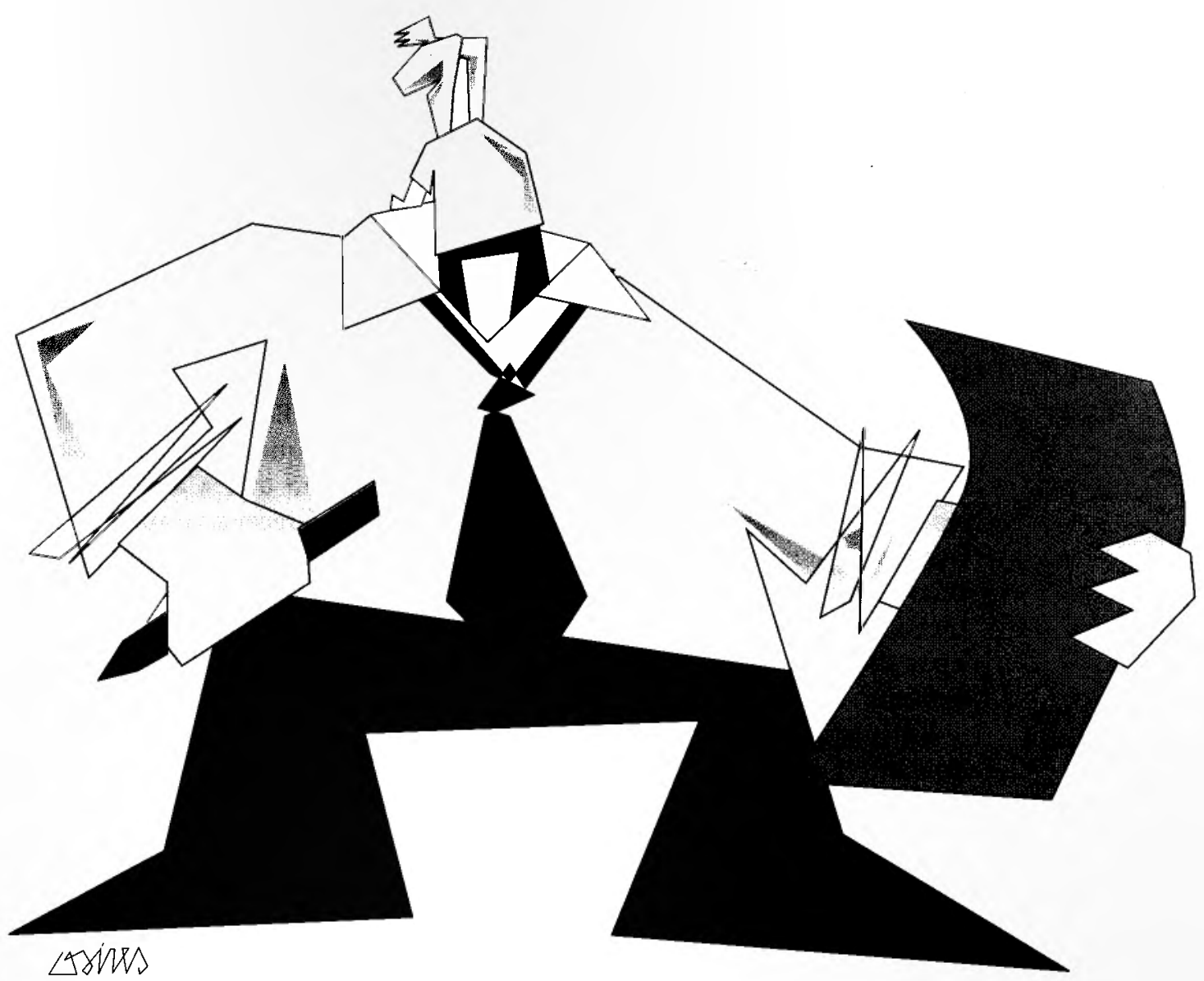

PALAVRAS-CHAVE:

pesquisa qualitativa, pesquisa documental, estudo de caso, etnografia, observação participante, entrevista, coleta de dados, análise de dados, análise de documentos.

\section{KEY WORDS:}

qualitative research, document study, case research, ethnography, participant observation, interview, data collecting, data analysis, documents analysis.

$\star$ Professora do Departamento de Educaçáo da UNESP, RIo Claro. 


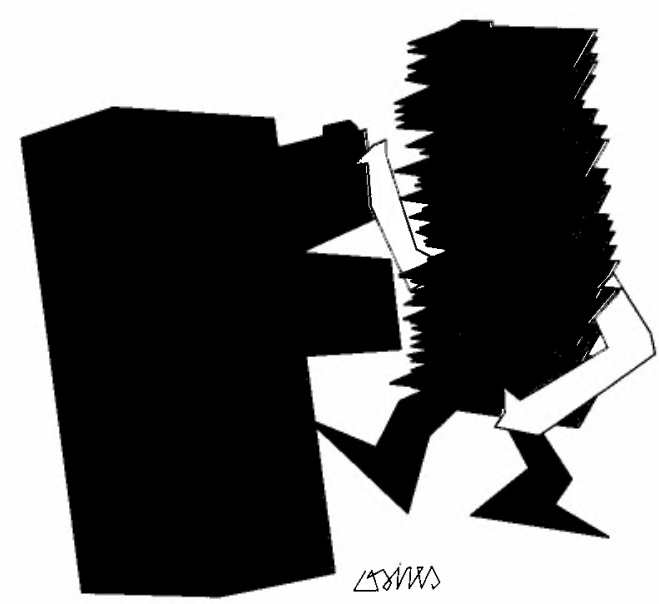

Exemplos concretos de aplicação da pesquisa documental, estudo de caso e etnografia em Administração de Empresas.

\author{
Examples of document study, case study and \\ ethnograph as applied to the area of Business \\ Administration.
}

1. GODOY, Arilda Schmidt. Introdução à pesquisa qualitativa e suas possibilidades. RAE - Revista de Administração de Empresas, São Paulo, v. 35, n. 2, p. $57-63$, mar./abr. 1995.

2. . Pesquisa qualitativa: tipos fundamentais. $R A E$ - Revista de Administração de Empresas, São Paulo, v. 35, $\mathrm{n}$. 3, p. 30-6, jan./fev. 1995.

3. BARTUNEK, J. M., BOBKO, P., VENKATRAMAN, N. Toward innovation and diversity in management research methods. Academy of Management Journal, Ada, v. 36, n. 6, p. 136273, Dec. 1993.

4. WHEELER, D. R. Content analysis: an analytical technique for international marketing research. International Marketing Review, Bradford, v. $5, \mathrm{n}$. 4, p. 34-40, Winter 1988. litativo constitui-se em importante contribuição à investigação das questões pertinentes à área. Dos trabalhos apresentados no fórum, dez foram escolhidos para compor um número especial da revista Academy of Management Journal, sendo quatro deles de natureza qualitativa. Uma síntese desses estudos pode ser encontrada em artigo de Bartunek, Bobko e Venkatraman ${ }^{3}$.

Para que possamos visualizar a contribuição que a abordagem qualitativa pode oferecer ao estudioso da área de Administração, acreditamos ser fundamental apresentar alguns exemplos que contemplem situações de investigação representativas desta vertente, a saber: a pesquisa documental, o estudo de caso e a etnografia. Por meio dos exemplos será possível perceber como realizam seu trabalho aqueles pesquisadores que optam por estudos qualitativos.

\section{USO DE PESQUISA DOCUMENTAL}

O estudo dos conteúdos presentes, de maneira explícita e/ou implícita, nas várias formas de comunicação utilizadas em marketing é bastante antigo. A partir de 1975, segundo Wheeler ${ }^{4}$, a utilização da "análise de conteúdo" enquanto instrumental metodológico para o estudo das propagandas, anúncios e promoções já era bastante significativa nos Estados Unidos.

$\mathrm{Na}$ área do marketing internacional, a análise dos conteúdos veiculados nas promostram que a pesquisa de cunho qua- 
pagandas tem facilitado a compreensão da crescente complexidade que cerca os ambientes multiculturais, tornando mais perceptíveis as sutis diferenças qualitativas que envolvem gostos, tradições e simbolismos - entre diferentes sociedades e setores de uma mesma sociedade.

Uma pesquisa desenvolvida por Singh e Huang ${ }^{5}$, onde os autores fazem uma análise comparativa do conteúdo dos anúncios publicados em revistas da Índia e Estados Unidos, ilustra essa preocupação. Nesse estudo, os pesquisadores detectaram que, até aproximadamente 1920 , a propaganda naqueles dois países era muito semelhante, diversificando-se, posteriormente, em função do crescimento econômico e do próprio desenvolvimento da área de marketing nos Estados Unidos. A partir daquela década, os anúncios americanos foram se tornando maiores, mais coloridos e mais envolvidos com temáticas que exploram aspectos relativos a alimentação, prestígio, aprovação social, apelo sexual, luxúria e segurança, acompanhando, desta forma, necessidades impostas por determinantes de natureza econômica, social e cultural.

Outro exemplo interessante é a pesquisa de Susuki ${ }^{6}$, que revelou uma mudança no padrão dos anúncios de empresas japonesas veiculados nas revistas Business Week e Newsweek, no período de 1965 a 1977. O estudo indicou que os anunciantes japoneses foram, gradualmente, aprendendo a adaptar suas estratégias de marketing, visando a tornar seus produtos mais competitivos no mercado americano. A utilização do procedimento de análise de conteúdo no exame deste processo de adaptação permitiu ao pesquisador identificar que determinadas etapas características marcavam a mudança ocorrida.

Wheeler ${ }^{7}$ chama ainda a atenção para algumas pesquisas que foram desenvolvidas com o objetivo de avaliar como os anúncios veiculados pelos grandes magazines em determinadas épocas retratam as atividades e ocupações desempenhadas por mulheres. Mostra que, em tais estudos, a utilização da análise de conteúdo permitiu aos autores acompanhar a evolução de determinada tendência social — relativa ao trabalho feminino - através do tempo.

Esses exemplos mostram que a pesquisa documental na área de marketing pode utilizar, de forma bastante proveitosa, a técnica de análise de conteúdo, considerada capaz de prover o investigador com informações relevantes, fidedignas e válidas. Resta também salientar que a obtenção desse tipo de conhecimento, de cunho social e cultural, é fundamental aos processos de tomada de decisão na área.

Outro exemplo interessante de pesquisa documental refere-se a um trabalho de 1976. Nele, o autor, Barry A. Turner ${ }^{8}$, analisa o conteúdo de três inquéritos públicos, referentes a diferentes tipos de acidentes: um desabamento numa mina de carvão, a colisão entre um grande caminhão de transporte e um trem, e um incêndio num complexo de lazer. Todos estes casos acon-

Embora não haja uma
forte tradição qualitativa na
pesquisa desenvolvida no
campo da Administração de
Empresas, é possível
perceber, a partir da década
de 70 , um crescente
aumento de interesse por
esse tipo de abordagem.

teceram na Inglaterra e envolveram perdas de vida e muitos prejuízos. No exame desses inquéritos o autor procurou identificar as condições - culturais e institucionais - que favoreceram as falhas de previsão que acabaram por provocar tais catástrofes. Uma análise das características do conjunto de providências organizacionais e administrativas, associadas aos três acidentes, serviu para uma compreensão mais acurada de como falhas de natureza organizacional, sedimentandas ao longo dos anos, acabam por favorecer a ocorrência de tais eventos.

Vale a pena ressaltar, mais uma vez, que a análise de documentos constitui-se numa valiosa técnica de abordagem de dados qualitativos, podendo ser também utiliza-
5. SING, P. N., HUANG, S. C. Some socio-cultural and psychological dominant of advertising in India: a comparative study. Journal of Social Psychology, Provincetown, n. 57, p. 113-21, June 1962.

6. SUSUKI, N. The changing pattern of advertising strategy by Japanese business in the US market: content analysis. Journal of International Business Studies, Columbia, v. 11, n. 1, p. 63-72, First Quarter 1980.

7. WHEELER, D. R. Op. cit

8. TURNER, B. A. The organizational and interorganizational development of disasters. Administrative Science Quarterly, New York, v. 21, n. 3, p. 378-97, Sep. 1976. 


\author{
Os resultados de um \\ recente fórum sobre \\ metodologia da pesquisa em \\ Administração, ocorrido nos \\ Estados Unidos, mostram \\ que a pesquisa de cunho \\ qualitativo constitui-se em \\ importante contribuição à \\ investigação das questões \\ pertinentes à área.
}

da para complementar informações obtidas em outras fontes. Como se observarão em alguns dos exemplos a seguir, documentos de diversos tipos foram utilizados, visando a prover o pesquisador com dados complementares para a melhor compreensão do problema investigado.

\section{USO DO ESTUDO DE CASO}

Para ilustrar o uso do estudo de caso na área de Administração, vamos apresentar, resumidamente, duas pesquisas: a de Rafaeli e a de Sauer e Anderson'. Ambas mostram, por meio da metodologia adota$\mathrm{da}$, os aspectos característicos desse tipo de estudo.

Rafaeli relata um estudo qualitativo que teve por objetivo analisar, em profundidade, a natureza das interações entre pessoas que atuam no setor de serviços. Para ele, a compreensão dos papéis desempenhados pelos empregados, quando em interação com os clientes, possibilitaria um maior conhecimento do ambiente vivenciado assim como da organização de esquemas teóricos explicativos do que ocorre nos encontros característicos da área de serviços.

O contexto escolhido para a realização da investigação foi uma cadeia de supermercados em Jerusalém, Israel, durante o inverno e a primavera de 1986 . Os sujeitos foram os caixas e clientes de seis lojas, randomicamente selecionadas. $\mathrm{O}$ estudo fez uma análise do papel dos caixas de supermercados, examinando a influência da gerência, dos colegas e clientes sobre o desempenho destes empregados.

Procurando situar o leitor, Rafaeli descreve, em primeiro lugar, o contexto em que se deu a pesquisa, ou seja, as características de funcionamento dos supermercados de Israel, bastante semelhantes às dos Estados Unidos. Todos os supermercados envolvidos no estudo possuíam um gerente, um supervisor de caixas e entre oito e quinze caixas. As funções desses empregados foram detalhadamente apresentadas.

Os dados foram coletados em observações participante e não-participante e entrevistas. A observação não-participante, realizada em todas as seis unidades envolvidas no estudo, foi desenvolvida de forma bastante discreta para que os observadores (auxiliares de pesquisa) passassem desapercebidos. A observação participante ocorreu mediante engajamento do pesquisador nos processos de solicitação de emprego, treinamento e trabalho como caixa. Teve a duração de três meses, durante os quais o pesquisador trabalhou num esquema de tempo parcial, 18 horas por semana. Entrevistas semi-estruturadas foram conduzidas com 30 caixas. As perguntas referiam-se ao trabalho que realizavam e às suas percepções sobre os clientes e seus comportamentos. As mesmas perguntas, de forma adaptada, foram feitas aos gerentes e supervisores. Trinta clientes também foram entrevistados.

A análise dos dados começou com algumas sessões de brainstorming entre os membros da equipe de pesquisa, adotando, a seguir, algumas orientações propostas por Miles e Huberman ${ }^{10}$. Um processo interativo entre dados e teoria ocorreu durante toda a análise, buscando corroborar a consistência do quadro teórico que estava sendo construído.

Os dados revelaram que os caixas gastam a maior parte do seu tempo em interação com os clientes, dos quais obtêm tanto feedback direto acerca do seu trabalho quanto vários outros tipos de informações. Assim, os clientes exercem uma influência direta sobre o trabalho dos caixas. As formas de manifestação desta influência associam-se a um conjunto de fatores como a proximidade física, o tempo que 
passam juntos, o fluxo de feedback e de informações entre eles, a quantidade de informações trocadas e o papel que o próprio caixa atribui ao cliente. Durante tais encontros, caixas e clientes desenvolvem determinados padrões de controle que passam a orientar suas interações. Interessantes e importantes diferenças foram encontradas nas percepções desses dois protagonistas, em relação às estratégias por eles adotadas para garantir o controle das interações que acontecem na situação de trabalho. Embora a influência da gerência sobre o trabalho dos caixas exista e seja entendida como legítima, é formal e considerada remota.

Para mostrar como estes fenômenos ocorrem no interior dos supermercados, Rafaeli descreve as situações de trabalho em que eles acontecem, utilizando, muitas vezes, a própria fala dos sujeitos como suporte para as suas interpretações.

$O$ outro trabalho selecionado para ilustrar a pesquisa do tipo estudo de caso, explorou a temática da inovação, considerada importante elemento na tentativa das organizações melhorarem sua eficiência $\mathbf{e}$ efetividade. O estudo, desenvolvido por Sauer e Anderson ${ }^{11}$, teve como objetivo investigar como o processo de inovação é percebido pelos diferentes níveis da hierarquia organizacional. Neste trabalho, $\mathrm{o}$ fenômeno da inovação foi estudado em dois hospitais do Serviço Nacional de Saúde da Inglaterra.

A metodologia empregada utilizou entrevistas, documentos e observações como principais fontes de coleta de dados. Durante seis meses foram conduzidas 26 semi-estruturadas, que duraram entre 25 e 70 minutos. Foram entrevistadas pessoas representativas de três diferentes níveis hierárquicos, às quais era solicitado que identificassem, segundo seu ponto de vista, os incidentes mais significativos e importantes ocorridos durante o processo de implantação de determinada inovação. Cada incidente identificado era, então, discutido em relação ao seu impacto, às circunstâncias que o precederam e aos seus efeitos na percepção individual do sujeito e no seu trabalho. Todas as entrevistas foram gravadas e posteriormente transcritas.
$\mathrm{Na}$ análise do conteúdo das transcrições, procurou-se identificar os temas comuns, comparados com o objetivo de identificar similaridades e diferenças nos processos de inovação dos dois hospitais. Procurou-se, também, verificar se a percepção da inovação era diferente para os três níveis hierárquicos envolvidos.

A metodologia qualitativa empregada possibilitou que os pesquisadores detectassem que a noção de inovação era percebida de forma bastante diferente pelos participantes. No entanto, três fatores influenciavam, decisivamente, as percepções in-

\section{$\mathrm{Na}$ área do marketing internacional, a análise dos conteúdos veiculados nas propagandas tem facilitado a compreensão da crescente complexidade que cerca os ambientes multiculturais, tornando mais perceptiveis as sutis diferenças qualitativas - que envolvem gostos, tradições e simbolismos - entre diferentes sociedades e setores de uma mesma sociedade.}

dividuais dos entrevistados: o seu grau de envolvimento no processo, a visão que estes tinham sobre os possíveis resultados da inovação, e o impacto da inovação sobre as suas práticas de trabalho e relacionamentos.

A partir destes resultados, os autores puderam desenvolver algumas recomendações para aqueles que pretendem introduzir inovações em suas organizações. $\mathrm{O}$ estudo forneceu ainda elementos para que Sauer e Anderson ${ }^{12}$ questionassem as tentativas de criação de taxionomias que visam a identificar diferentes tipos de inovação. Para esses pesquisadores, as taxionomias existentes não conseguem apreender a complexidade do fenômeno em questão, nem dão conta da diversidade dos processos envolvidos na condução de diferentes tipos de inovação.
11. SAUER, J., ANDERSON, N. Op. cit.

12. Idem, ibidem. 


\section{USO DA ETNOGRAFIA}

Para exemplificar a pesquisa de caráter etnográfico, vamos utilizar o trabalho de Gioia e Chittipeddi ${ }^{13}$. Estes autores estudaram os estágios iniciais de um processo de mudança estratégica ocorrido em uma grande universidade pública dos Estados Unidos, após a chegada do seu novo presidente. A pesquisa enfocou, de maneira especial, o papel do presidente e os processos subjacentes à iniciação dessa mudança. Duas questóes foram ainda examinadas: como o presidente e a alta administração entendiam o esforço de mudança $e$ as formas como tal visão foi comunicada $e$ entendida pelos grupos envolvidos, gerando diferentes atitudes em relação a ela.

Levando em consideração os aspectos básicos da abordagem qualitativa, os autores consideraram que, dada a natureza do fenômeno a ser investigado (mudança estratégica), a pesquisa deveria ser etnográfica.

Pressupondo que tanto a compreensão de um evento quanto a ação que sobre ele se exerce derivam de um sistema de significados construídos socialmente, a análise desta estrutura de significados e dos processos pelos quais esta se altera foi considerada fundamental ao estudo da "mudança estratégica". Compreender um evento a partir dos significados atribuídos pelos membros da organização exigiu, no entanto, que o pesquisador adquirisse um profundo conhecimento da cultura da organização, no caso, como referido, uma universidade. A necessidade de interação com as pessoas que estavam vivenciando o esforço de mudança estratégica constituiu, assim, elemento decisivo na escolha da etnografia como a forma de pesquisa a ser adotada.

Tendo em vista que a observação participante caracteriza a investigação etnográfica, o pesquisador adotou dois papéis, participando das atividades da organização ao mesmo tempo que as observava. $\mathrm{Na}$ busca da compreensão daquela cultura organizacional, tentou-se suspender suposições preexistentes, objetivando-se, inicialmente, descobrir como os membros da organização viam e interpretavam suas experiências em relação ao evento estuda-

\author{
A necessidade de interação \\ com as pessoas que estavam \\ vivenciando o esforço de mu- \\ dança estratégica \\ constituiu, assim, elemento \\ decisivo na escolha da \\ etnografia como a forma de \\ pesquisa a ser adotada.
}

do. Nesse sentido, cada interação e experiência passou a se constituir num dado a ser registrado, o que resultou numa grande quantidade de informações para análise.

O trabalho de campo durou dois anos e meio. Neste período, o pesquisador teve contato direto, quase que diariamente, com a presidência e a alta administração da universidade. Realizou entrevistas (gravadas) com cada um desses informantes, nos vários estágios do processo de mudança estratégica. As entrevistas procuraram explorar como eles percebiam a mudança e o papel do presidente enquanto iniciador $e$ administrador deste processo.

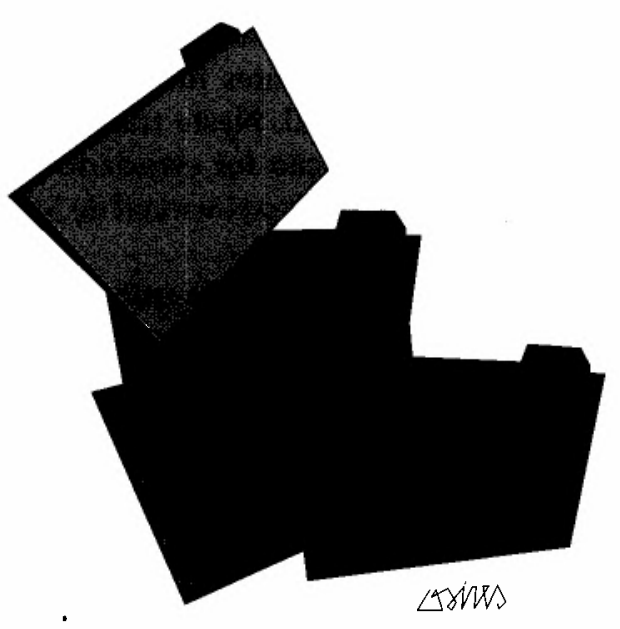

Seguindo uma tradição da etnografia, o pesquisador organizou um diário dos eventos e atividades ocorridos durante o seu tempo de permanência no campo. Assim, os dados primários foram obtidos a partir das transcriçōes das entrevistas e do registro das observações. $O$ pesquisador também teve acesso a cópias de memorandos internos e relatórios confidenciais, que 
foram considerados fontes de dados secundários.

Um membro da alta administração concordou em servir como revisor dos dados, descritos e interpretados na forma de resultados e conclusões. Este indivíduo tinha um papel central na administração e era um pesquisador atuante, o que lhe conferia as qualidades necessárias para analisar a precisão e credibilidade das interpretações que emergiam dos dados. Sua função era a de concordar ou não com as interpretações dos pesquisadores, validando-as ou sugerindo caminhos para novas e/ou adicionais análises. Esse revisor foi capaz de apontar lacunas nos dados e oferecer comentários críticos sobre as descobertas etnográficas e as análises teóricas realizadas.

A análise dos dados foi feita em duas etapas. Foi preparado um relatório inicial, sob um enfoque mais narrativo, de caráter jornalístico, no qual utilizaram-se as palavras e expressões dos membros da organizaçāo. Nesta primeira etapa, buscou-se captar os temas recorrentes e os padróes identificados nas observações e relatos dos informantes. Estes resultados forneceram uma rica narrativa que possibilitou a identificação dos elementos que compunham o sistema de significados dos participantes do processo de mudança, apontando, ainda, "pistas" sobre a forma de gerenciamento de tal processo. No entanto, não sugeriam uma clara estrutura teórica que servisse para a compreensão do processo de instigação envolvido nos estágios iniciais da mudança planejada. Assim, uma segunda análise dos dados foi desenvolvida, visando a discernir possíveis dimensões e/ou padrões subjacentes aos dados e resultados iniciais.

Nessa segunda etapa, os pesquisadores procuraram derivar dos dados novas explicações e interpretações, buscando, num esforço de abstração, configurar uma nova perspectiva teórica. É importante ressaltar que o esforço de teorização a partir dos dados reflete o enfoque indutivo característico dos estudos qualitativos. Nessa etapa do trabalho, utilizou-se também (conforme recomendam os especialistas em pesquisa qualitativa) um pesquisador “de fora" que, não tendo participado diretamente da fase anterior, supostamente teria melhores condições de proceder a uma análise mais precisa dos dados.

Assim, empregando vários procedimentos metodológicos para análise dos dados qualitativos, os autores conseguiram revelar aspectos da estrutura subjacente aos eventos que circundavam o processo de iniciação da mudança estratégica. Detectouse que o papel fundamental do presidente da universidade, enquanto incentivador desse processo, poderia ser compreendido em termos de dois conceitos que funcionaram então como "lentes" teóricas, possibilitando um caminho alternativo de se "ver", compreender, os estágios iniciais de um processo de mudança estratégica.

$$
\begin{gathered}
\text { Compreender um } \\
\text { evento a partir dos } \\
\text { significados atribuídos pelos } \\
\text { membros da organização } \\
\text { exigiu, no entanto, que o } \\
\text { pesquisador adquirisse um } \\
\text { profundo conhecimento da } \\
\text { cultura da organização, no } \\
\text { caso, como referido, uma } \\
\text { universidade. }
\end{gathered}
$$

\section{PALAVRAS FINAIS}

Acreditamos que os exemplos apresentados ilustram as possibilidades de utilização da pesquisa qualitativa no exame de questôes pertinentes à Administração de Empresas. Leitores interessados neste tipo de abordagem poderão encontrar outros exemplos em várias revistas da área, das quais destacamos a Administrative Science Quarterly e a Academy of Management Journal, que nos parecem ser as que mais têm publicado artigos sobre pesquisas na linha qualitativa.

\section{7}

